\title{
Duplex real-time PCR for detection and quantification of monodon baculovirus (MBV) and hepatopancreatic parvovirus (HPV) in Penaeus monodon
}

\author{
Kathy F. J. Tang*, Donald V. Lightner \\ Department of Veterinary Science and Microbiology, University of Arizona, Tucson, Arizona 85721, USA
}

\begin{abstract}
We describe a duplex real-time PCR assay using TaqMan probes for the simultaneous detection of monodon baculovirus (MBV) and hepatopancreatic parvovirus (HPV). Both MBV and HPV are shrimp enteric viruses that infect intestinal and hepatopancreatic epithelial cells. Both viruses can cause significant mortalities and depressed growth in infected larval, postlarval, and early juvenile stages of shrimp, and thus present a risk to commercial aquaculture. In this duplex assay, we combined 2 single real-time PCRs, amplifying MBV and HPV, in a one-tube PCR reaction. The 2 viruses were distinguished by specific fluorescent labels at the $5^{\prime}$ end of TaqMan probes: the MBV probe was labeled with dichlorodimethoxyfluorescein (JOE), and the HPV probe was labeled with 6-carboxyfluorescein (FAM). The duplex real-time PCR assay was performed in a multi-channel real-time PCR detection system, and MBV and HPV amplification signals were separately detected by the JOE and FAM channels. This duplex assay was validated to be specific to the target viruses and found to have a detection limit of single copies for each virus. The dynamic range was found to be from 1 to $1 \times 10^{8}$ copies per reaction. This assay was further applied to quantify MBV and HPV in samples of infected Penaeus monodon collected from Malaysia, Indonesia, and Thailand. The specificity and sensitivity of this duplex real-time PCR assay offer a valuable tool for routine diagnosis and quantification of MBV and HPV from both wild and farmed shrimp stocks.
\end{abstract}

KEY WORDS: Duplex real-time PCR $\cdot$ Monodon baculovirus $\cdot$ Hepatopancreatic parvovirus $\cdot$ Penaeus monodon

Resale or republication not permitted without written consent of the publisher

\section{INTRODUCTION}

Both monodon-type baculovirus (MBV) and hepatopancreatic parvovirus (HPV) are enteric viruses. These viruses have the same target tissues, infecting the hepatopancreatic and midgut epithelial cells of penaeid shrimps (Lightner \& Redman 1981, Chong \& Loh 1984), and co-infected Penaeus monodon are often found in SE Asia (Chantanachookin et al. 1993, Flegel et al. 1999, Manivannan et al. 2002). Outbreaks of these viruses can be devastating to aquaculture production, as infections of larval to early juvenile stages can result in 90 to $100 \%$ mortality (Lightner \& Redman 1985, Lightner 1996). In contrast, infections of larger juveniles and adults usually do not cause mortality, and the infected individuals show no symptoms of disease. However, the severity of infection, especially with regard to HPV, has been associated with growth retardation (Flegel et al. 1999, 2004, Chayaburakul et al. 2004). In addition, infected juvenile and adult shrimp can be carriers and constitute a serious threat to production if undetected.

The prevalence of infection by these viruses has been moderate to high in recent years. MBV was found to infect up to $20 \%$ in populations of wild Penaeus monodon in Asia (Manivannan et al. 2004, de la Pena et al. 2008). HPV can infect 11 species of penaeid shrimps (OIE Aquatic Animal Disease Cards 2007) over a wide geographic distribution. HPV is highly prevalent in some areas, it has been found in nearly 
$100 \%$ of the populations of wild P. monodon in Africa and also in the wild stock of $P$. merguiensis in New Caledonia (Tang et al. 2008). In India, the prevalence of HPV was found in $46 \%$ of the wild populations (Manjanaik et al. 2005). For farmed P. monodon, 31 to $62 \%$ of shrimp were found to be HPV-positive in India and Thailand (Umesha et al. 2003, Flegel et al. 2004).

The viral structures for MBV and HPV are distinctive. MBV is a large $(270 \times 72 \mathrm{~nm})$, rod-shaped, enveloped baculovirus with a genome size estimated to be between 80 and $160 \mathrm{~kb}$ (Mari et al. 1993). However, HPV is a small $(22 \mathrm{~nm})$, icosahedral parvovirus that contains a single-stranded DNA genome of $\sim 6 \mathrm{~kb}$ (Bonami et al. 1995, Sukhumsirichart et al. 2006, La Fauce et al. 2007a).

Development of a duplex real-time PCR assay will allow for simultaneous detection of 2 viruses in the same reaction, which is more cost-effective than assaying for each virus separately. Two real-time HPV methods have been developed from the Australian and Korean isolates, respectively (La Fauce et al. 2007b, Yan et al. 2010). However, the highest number of mismatches was found in the isolate from Thailand with both assays. Therefore, we first developed a HPVth (based on the Thai HPV genome, the 'th' stands for Thailand) realtime PCR and then combined it with the real-time MBV PCR method described by Yan et al. (2009). This duplex real-time PCR assay was applied in the quantification of HPV (Thai isolate) and MBV in infected shrimp collected in Malaysia, Indonesia and Thailand.

\section{MATERIALS AND METHODS}

Shrimp and viruses. A collection of MBV- and/or HPV-infected shrimp tissue and fecal samples were used to determine the specificity of the real-time PCR (Table 1). These samples were collected from 1991 to 2009 and stored at $-70^{\circ} \mathrm{C}$ in the Aquaculture Pathology Lab at the University of Arizona, Tucson, USA. They were determined to be positive for MBV and/or HPV by the conventional PCR using specific primers: MBV261F (5'-AAT CCT AGG CGA TCT TAC CA-3'), MBV261R (5'-CGT TCG TTG ATG AAC ATC TC-3'), HPV-2F (5'-GGA AGC CTG TGT TCC TGA CT-3'), HPV-2R (5'-CGT CTC CGG ATT GCT CTG AT-3') (Surachetpong et al. 2005, Tang et al. 2008). Among these, Penaeus monodon samples collected from Malaysia, Indonesia and Thailand were also used for quantification of viral load with the duplex real-time PCR assay. The Malaysian samples consist of: (1) 8 shrimp (mean weight: $15.30 \mathrm{~g}$ ) from a normal growth pond, and (2) 31 shrimp (mean weight: $7.25 \mathrm{~g}$ ) from a stunted growth pond; these shrimp were from the same population.
Table 1. Species and origin of monodon baculovirus (MBV)and/or hepatopancreatic parvovirus (HPV)-infected shrimp Penaeus spp.

\begin{tabular}{|llll|}
\hline Virus detected & Origin & Host species & Year \\
\hline MBV & Taiwan & P. monodon & 1991 \\
HPV & Taiwan & P. monodon & 1991 \\
HPV and MBV & Thailand & P. monodon & 1992 \\
HPV & China & P. chinesis & 1999 \\
MBV & Thailand & P. monodon & 2001 \\
HPV and MBV & Malaysia & P. monodon & 2003 \\
HPV & Indonesia & P. monodon & 2005 \\
HPV & Mozambique & P. monodon & 2005 \\
HPV & New Caledonia & P. merguiensis & 2006 \\
HPV & Madagascar & P. monodon & 2007 \\
MBV & The Philippines & P. monodon & 2009 \\
aFecal sample from P. monodon cultured in Thailand \\
\hline
\end{tabular}

DNA extraction. DNA was extracted from the hepatopancreas of shrimp with a High Pure PCR Template Preparation Kit (Roche Bioscience). The concentration of DNA was determined by photospectroscopy at $260 \mathrm{~nm}$ using the NanoDrop ND-1000 UV-Vis spectrophotometer (NanoDrop Technologies).

Positive control plasmids for MBV and HPVth realtime PCR assays. The cloning of positive control plasmid for MBV was described in Yan et al. (2009). The concentration of plasmid DNA was determined and diluted 10-fold serially in sheared salmon sperm DNA $\left(20 \mathrm{ng} \mathrm{hl}^{-1}\right)$ and subjected to the real-time PCR assays.

For HPV, the positive control plasmid was prepared from a 572 bp DNA fragment (nucleotides 1574 to 2145, GenBank no. DQ002873) amplified from a Malaysian Penaeus monodon sample using primers HPVth-572F (5' -TTT GAA CAT TGG AAC GAC AA$3^{\prime}$ ) and HPVth-572R (5'-TTG TCA TTG TTT TCA CCA CCA-3'). The amplicons were purified with a QIAquick PCR Purification Kit (Qiagen) and ligated with the pGEM-T-Easy vector (Promega). The plasmid DNA (designated as pHPVth-1) was purified with an E.Z.N.A. Plasmid Miniprep Kit (Omega Bio-tek). It was sequenced using an automatic DNA sequencer, 3730 DNA analyzer (Applied Biosystems) at the University of Arizona to confirm that it contains the target sequence of primers/TaqMan probe for HPVth real-time PCR. Its concentration was determined and expressed as number of molecules (i.e. copies) per reaction.

Real-time PCR primers and TaqMan probes. For MBV real-time PCR, we adopted a procedure recently developed in our laboratory (Yan et al. 2009); the target sequence of this PCR is located in an open reading frame (ORF) containing a conserved domain of phage integrase (pfam00589, analyzed using sequence of GenBank no. EU246944). The sequences of reverse primer and TaqMan probe were the same as that described in Yan et al. (2009) (Table 2). The forward 
primer (designated as MBV-F in the present study) was slightly modified to start at nucleotide position 30 (GenBank no. AY494591) not at position 29 as described originally. The new forward primer MBV-F had a similar melting temperature $\left(\mathrm{Tm} ; 58.6^{\circ} \mathrm{C}\right.$ at $50 \mathrm{mM} \mathrm{NaCl})$ to the reverse primer MBV-R $(\mathrm{Tm}=$ $58.4^{\circ} \mathrm{C}$ ) as determined by the Primer Express software (version 2.0, Applied Biosystems). Thus, they are compatible in the PCR. The size of MBV amplicon becomes 134 bp. The TaqMan probe was labeled with dichlorodimethoxyfluorescein (JOE) at the $5^{\prime}$ end and black hole quencher 1 (BHQ-1) at the 3' end.

For HPV, we developed a set of primers/probe based on a Thai isolate, because most of the Penaeus monodon samples to be analyzed were from SE Asia. With Australian HPV real-time PCR (La Fauce et al. 2007b), the sequence alignment in the primers/probe binding sites showed 9 to 15 mismatched nucleotides in the genomic sequences of various isolates (see Fig. 1A). For Korean HPV real-time PCR (Yan et al. 2010), there were 5 to 15 mismatched nucleotides in the primers/ probe targeted sequences (see Fig. 1B) The highest number of mismatches (15) was found in the isolate from Thailand with both assays. The HPVth ('th' stands for Thailand) real-time PCR primers and TaqMan probe were selected from the ORF2 (which may encode the non-structural protein 1) of the Thai isolate (GenBank no. DQ002873). Primer Express software was used to design the primers and probe, their sequences are listed in Table 2, and the sequence alignment among various isolates is shown in Fig. 1C. The HPV TaqMan probe was labeled with 6-carboxyfluorescein (FAM) at the 5' end and BHQ-1 at the 3' end. All the PCR primers and TaqMan probes were purchased from Eurofins MWG Operon.

Single and duplex (MBV and HPVth) real-time PCR assays. The specificity test for MBV (or HPVth) real- time PCR was carried in a $20 \mu$ reaction mixture containing $10 \mu \mathrm{l}$ of PerfeCta qPCR SuperMix (Quanta BioSciences), primers (300 nM each) and probe (150 nM). The single real-time PCR was performed on the Mastercycler ep realplex (Eppendorf) with the following conditions: initial denaturation at $95^{\circ} \mathrm{C}$ for $5 \mathrm{~min}$, followed by 40 cycles of amplification at $95^{\circ} \mathrm{C}$ for $15 \mathrm{~s}$ and annealing/extension at $60^{\circ} \mathrm{C}$ for $1 \mathrm{~min}$. Amplification data were collected and analyzed with the Realplex 2.0 software (Eppendorf). The detection and quantification of MBV and HPV were from the channels detecting JOE and FAM, respectively.

The duplex real-time PCR assay was carried out in a $25 \mu$ reaction mixture containing $12.5 \mu \mathrm{l}$ of PerfeCTa multiplex QPCR SuperMix, primers (500 nM each; using $250 \mathrm{nM}$ of HPVth primers when quantifying Malaysian samples) and probes (150 nM each). Duplex real-time PCRs were performed in the same cycling profile as described above. Each sample was analyzed in duplicate.

Statistical analysis. For Malaysian samples, the MBV and HPV viral loads were compared between groups (normal growth and stunted growth) by 1-way analysis of variance (ANOVA), and their correlation was analyzed by a Pearson test with Statistix 9 (Analytical Software). Probability values provided the likehood that variations between groups arose from chance.

\section{RESULTS}

\section{Specificity and sensitivity of the single real-time PCR detecting MBV or Thai HPV}

We used single real-time PCR to evaluate the specificity for the detection of MBV and HPV. For MBV, the single real-time PCR results showed this assay can

Table 2. Sequence information of primers and probes used for the duplex real-time PCR. HPV: hepatopancreatic parvovirus, MBV: monodon baculovirus

\begin{tabular}{|c|c|c|c|}
\hline Primers/probes & Sequence $\left(5^{\prime}-3^{\prime}\right)$ & $\begin{array}{l}\text { Nucleotide position } \\
\text { (GenBank no.) }\end{array}$ & $\begin{array}{l}\text { Fluorophore }\left(5^{\prime}\right) / \\
\text { Quencher( }\left(3^{\prime}\right)\end{array}$ \\
\hline \multicolumn{4}{|c|}{ MBV (amplicon = 134 bp) } \\
\hline MBV-F & CTACCATAAGCTAGCATACGTCCTTTT & $\begin{array}{l}\text { 30-56 (AY494591) } \\
\text { or } 1225-1199(\text { EU246944) }\end{array}$ & 6-JOE/BHQ-1 \\
\hline MBV-R & AAAGGTCAGCAAAAAACACTCAATT & $\begin{array}{l}\text { 139-163 (AY494591) } \\
\text { or 1092-1116 (EU246944) }\end{array}$ & \\
\hline MBV-P1 & ACССTCTACCGATATGGTATCAATGTCTGGAGTT & $\begin{array}{l}\text { 89-122 (AY494591) } \\
\text { or 1166-1133 (EU246944) }\end{array}$ & \\
\hline \multicolumn{4}{|c|}{ Thai HPV (amplicon = 81 bp) } \\
\hline HPVth-F & CGCGGCTACGAGAAGATACTTCA & 1817-1839 (DQ002873) & 6-FAM/BHQ-1 \\
\hline HPVth-R & CGACGAAGGCGATGTCTTCTG & 1897-1877 (DQ002873) & \\
\hline HPVth-P1 & ACGACAACAAACAACTATGGGAGGACCTAGGAC & $1842-1874(\mathrm{DQ} 002873)$ & \\
\hline
\end{tabular}


detect MBV isolates collected from Thailand (threshold cycle number, $\mathrm{Ct}=25$ for a fecal sample collected in 2001; $\mathrm{Ct}=27$ for a hepatopancreas sample collected in 1992), Malaysia ( $\mathrm{Ct}=23)$, Taiwan $(\mathrm{Ct}=28)$, and the Philippines $(\mathrm{Ct}=34$ ) (amplification plots not shown; the result of Thailand fecal sample analysis was already reported in Yan et al. (2009).

For HPV, a pair of HPV primers to be used in conjunction with TaqMan probe were designed from the ORF2 region of the Thai HPV genome. The sequence alignment of the $81 \mathrm{bp}$ amplicon showed 7 to 10 mismatched nucleotides within the primers/probe binding sites (containing 77 nucleotides) in the target sequence of 5 other geographic isolates (Fig.1C). This HPVth real-time PCR was shown to be specific to HPV, and it can be used to detect HPV-infected shrimp samples collected from 8 geographically diverse sites in SE Asia (Thailand, Taiwan, China, Indonesia, Malaysia), Africa (Madagascar, Mozambique), and New Caledonia over a wide range of
Ct values, from 19 to 33 (Fig. 2). Purified HPV virions (Korean isolate) were also detected with a Ct value of 12 . This real-time PCR did not detect any amplifications from shrimp DNA (extracted from Penaeus monodon and $P$. vannamei), or from other shrimp viruses including IHHNV, WSSV, MBV (data not shown).

By testing concentrations of 1 to $1 \times 10^{8}$ copies of positive control plasmid DNA, the sensitivity of $\mathrm{MBV}$ and HPVth real-time were shown to be within 1 to 10 copies. These 2 (MBV and HPVth) single real-time PCRs were then combined in a one-tube PCR reaction to form a duplex assay.

\section{Sensitivity and dynamic range of the duplex real-time PCR}

We performed the duplex real-time PCR with the PerfeCTa Multiplex qPCR Supermix, which is

\section{A) Australia HPV}
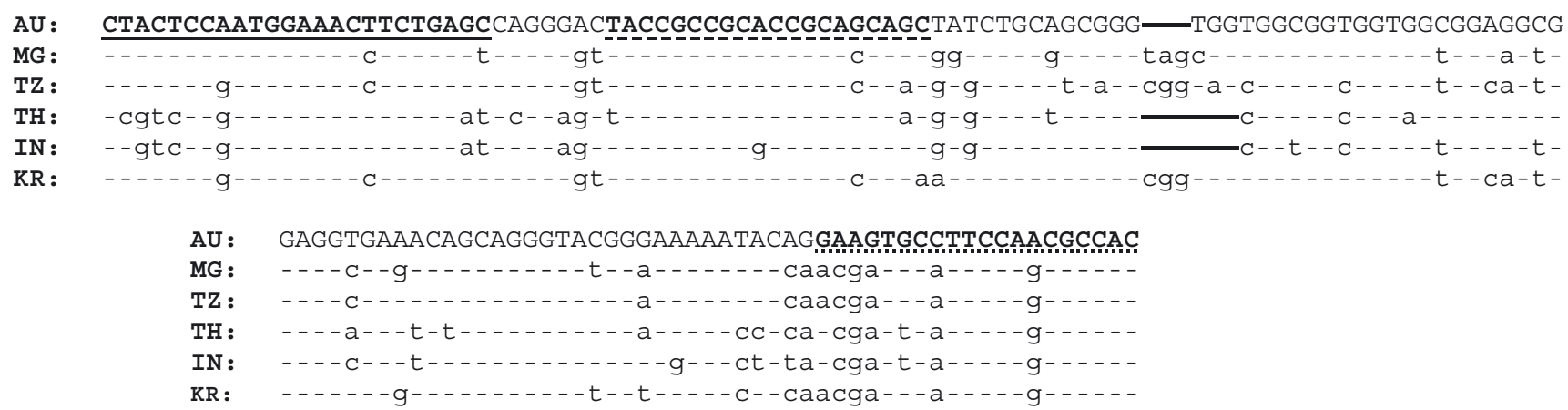

\section{B) Korea HPV}

$\mathrm{KR}$

TZ :

MG :

$\mathrm{AU}$ :

IN :

TH :
ACTTTGTTGGCGGCGATAGTACTGCGCAGAACGATCAGAGCAATCCGAAGACGGAGGGAGCTAACGAAATTAACGACAGAACGACATCGACA

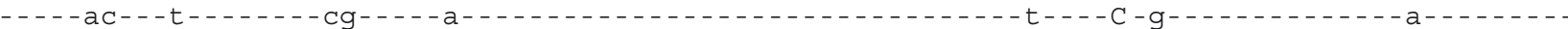

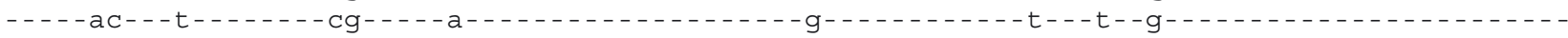

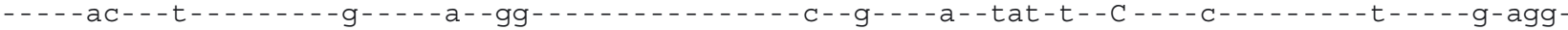

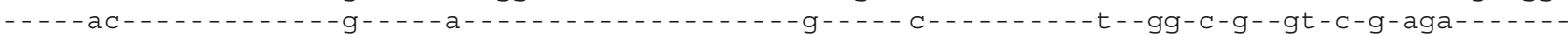

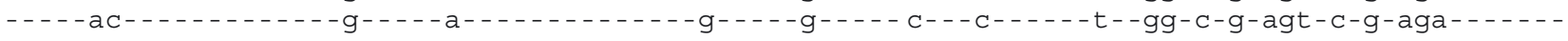

C) Thailand HPV

Fig. 1. Variation of nucleotide sequence within 3 hepatopancreatic parvovirus (HPV) real-time PCR amplicons among (A) Australian HPV, (B) Korean HPV, and (C) Thai HPV. Nucleotide sequence of forward primes (solid underlines), complementary sequence for reverse primer (dotted underlines), and TaqMan probe binding region (dashed underlines) are shown. TH: Thai HPV (GenBank no. DQ002873), KR: Korena HPV (GenBank no. AY008257), AU: Australian HPV (GenBank no. DQ458781), IN: Indian HPV (GenBank no. FJ 410797), MG: Madagascan HPV genome (GenBank no. EU247528), TZ: Tanzanian HPV (GenBank no. EU588991). Thick black lines: gap in the sequence alignment 


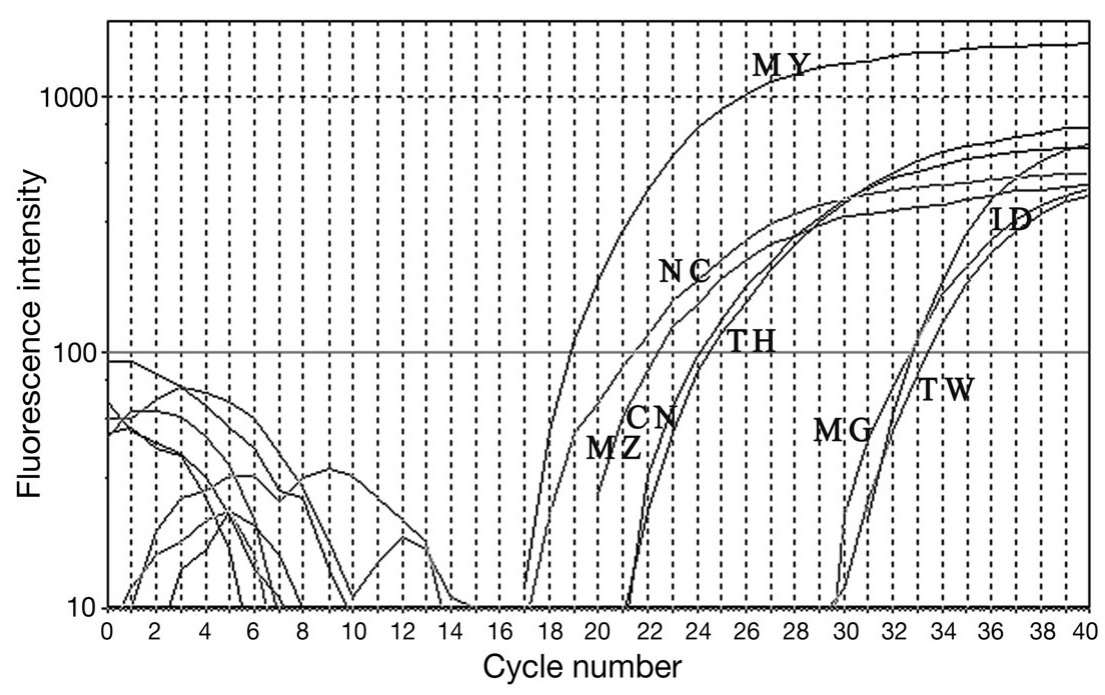

Fig. 2. Amplification plots of hepatopancreatic parvovirus (HPV) isolates detected by HPVth real-time PCR. DNA was extracted from HPV-infected penaeid shrimp from Malaysia (MY), New Caledonia (NC), Mozambique (MZ), China

$(\mathrm{CN})$, Thailand (TH), Madagascar (MG), Taiwan (TW), and Indonesia (ID) approximately 10 times more efficient than the qPCR Supermix. We tested 6 HPV samples with the Multiplex qPCR Supermix, and the $\mathrm{Ct}$ values were 3.4 cycles (mean) less than the $\mathrm{Ct}$ values obtained from using qPCR Supermix. The detection limits of the duplex realtime PCR assays proved to be 1 copy for MBV and for HPV (Fig. 3). By gel electrophoresis, the MBV amplicons showed the expected size of $134 \mathrm{bp}$ and the amplicons could be visualized down to 1 copy. The HPV band intensity was relatively weak and only could be visualized at 100 copies; this may be due to the smaller $(81 \mathrm{bp})$ fragment. With real-time $\mathrm{PCR}$, the fluorescence intensity $(\Delta \mathrm{Rn}=2000$, arbitrary unit) is much stronger with FAM; and 1 copy of HPV can be consistently detected. The $\Delta \mathrm{Rn}$ for JOE is 800 by the Mastercyler ep realplex real-time PCR system.

The dynamic ranges are from 1 to $1 \times 10^{8}$ copies for both MBV and HPVth in the duplex real-time PCR (Fig. 3). The average coefficient of regression of the standard curves ranged from 0.97 to 0.99 from the results of 10 assays. We obtained similar amplification efficiencies for both single and duplex real-time PCRs. For MBV, mean efficiencies $(n=3)$ were 1.15 and 1.25 for single and duplex reactions, respectively. For HPV, means $(n=3)$ were 0.99 and 0.97 for single and duplex reactions, respectively.

\section{Quantification of HPV and MBV in the infected Penaeus monodon by the duplex PCR assay}

\section{Malaysian Penaeus monodon samples}

With Penaeus monodon collected from Malaysia, we sequenced a $572 \mathrm{bp}$ HPV fragment flanking the realtime PCR amplicon, the result was $100 \%$ identical to the sequence of the Thai HPV isolate (GenBank no. DQ002873). Thus, the nucleotide sequence of HPVth primers/TaqMan probe completely matched to its target site. By the duplex real-time PCR, HPV viral load was estimated 5 orders of magnitude higher than that of MBV, although the concentration of HPVth primers was limited to prevent the HPVth DNA competing with MBV DNA templates for dNTPs and enzyme in the same tube. We tested the HPVth-F/R primers over a concentration range from 600 to $100 \mathrm{nM}$ with a HPV sample of $10^{13}$ copies per $\mu \mathrm{g}$ DNA. The $\mathrm{Ct}$ values primer concentrations of $600 \mathrm{nM}$ and $250 \mathrm{nM}$ were close with 7.40 and 7.61, respectively. Using $200 \mathrm{nM}$ of 
Table 3. Quantities (mean $\pm \mathrm{SD}$, range in parentheses) of hepatopancreatic parvovirus (HPV) and monodon baculovirus (MBV) in the Penaeus monodon collected in Malaysia, Indonesia, and Thailand

\begin{tabular}{|c|c|c|}
\hline $\begin{array}{l}\text { Origin } \\
\text { Growth }\end{array}$ & $\begin{array}{c}\text { HPV } \\
\text { (copies } \mu \mathrm{g} \mathrm{DNA}{ }^{-1} \text { ) }\end{array}$ & $\begin{array}{c}\text { MBV } \\
\text { (copies } \mu g \mathrm{DNA}^{-1} \text { ) }\end{array}$ \\
\hline \multicolumn{3}{|l|}{ Malaysia } \\
\hline Stunted & $\begin{array}{c}2.76 \times 10^{12} \pm 5.28 \times 10^{12}, \mathrm{n}=32 \\
\left(9.04 \times 10^{6} \text { to } 1.86 \times 10^{13}\right)\end{array}$ & $\begin{array}{c}1.94 \times 10^{7} \pm 1.00 \times 10^{9}, \mathrm{n}=32 \\
\left(3.89 \times 10^{3} \text { to } 5.70 \times 10^{9}\right)\end{array}$ \\
\hline Normal & $\begin{array}{c}2.35 \times 10^{12} \pm 6.48 \times 10^{12}, \mathrm{n}=8 \\
\left(3.02 \times 10^{7} \text { to } 1.84 \times 10^{13}\right)\end{array}$ & $\begin{array}{c}1.96 \times 10^{7} \pm 3.92 \times 10^{7}, \mathrm{n}=8 \\
\left(1.14 \times 10^{4} \text { to } 1.15 \times 10^{8}\right)\end{array}$ \\
\hline Indonesia & $\begin{array}{c}2.54 \times 10^{5} \pm 5.93 \times 10^{5}, \mathrm{n}=9 \\
\left(200 \text { to } 1.80 \times 10^{6}\right)\end{array}$ & Not detected \\
\hline Thailand & $\begin{array}{c}3.47 \times 10^{6} \pm 1.37 \times 10^{7}, \mathrm{n}=30 \\
\left(200 \text { to } 7.28 \times 10^{7}\right)\end{array}$ & $\begin{array}{c}4.18 \times 10^{6} \pm 1.79 \times 10^{7}, \mathrm{n}=30 \\
\left(676 \text { to } 9.84 \times 10^{7}\right)\end{array}$ \\
\hline
\end{tabular}

Thai Penaeus monodon samples

For 30 Penaeus monodon collected from Thailand, the 572 bp HPV amplicons were also sequenced and analyzed. The results showed that they were $95 \%$ identical to the published Thai sequence (Sukhumsirichart et al. 2006). When comparing with the sequence of HPVth primers/probe binding sites, there are 3 mismatched nucleotides (all adenine to guanine nucleotide changes) locating at nucleotide position 12 of the forward primer and nucleotide positions 11 and 29 in the probe-binding region. By the duplex real-time $\mathrm{PCR}$, these 30 shrimp were all

primers, the $\mathrm{Ct}$ value increased to 9.58. Thus $250 \mathrm{mM}$ of HPVth primers were used for quantifying HPV in these samples. The samples that were out of the dynamic range of the standard curve were further diluted and re-quantified by the duplex real-time PCR assay.

All 39 Penaeus monodon collected in Malaysia were found to be infected with both HPV and MBV by this duplex assay. For the shrimp reported to have stunted growth, the HPV viral loads were high, up to $1.86 \times$ $10^{13}$ with a mean of $2.76 \times 10^{12}$ copies per $\mu \mathrm{g}$ DNA (Table 3 ). HPV viral load in normally grown shrimp was similar (mean: $2.35 \times 10^{12}$ copies $\mu \mathrm{g}$ DNA), but the variability was high within the 2 groups and there was no significant (ANOVA, $F_{1,38}=0.58, \mathrm{p}=0.4500$ ) difference in mean HPV viral loads between them. MBV viral loads averaged $1.96 \times 10^{7}$ and $1.94 \times 10^{7}$ copies per $\mu \mathrm{g}$ DNA in normal and stunted growth samples, respectively (Table 3 ); and, again, there was no significant $\left(F_{1,38}=0.06, \mathrm{p}=0.8029\right)$ difference between them. We also analyzed the relationship of MBV and HPV viral loads from these 39 shrimp, the result showed no correlation ( $p=0.1504$ by the Pearson test) between HPV and MBV viral loads.

\section{Indonesian Penaeus monodon samples}

For Penaeus monodon collected from Indonesia, 572 bp HPV fragments were amplified and sequenced revealing $99.9 \%$ identity (1 mismatched nucleotide within the $572 \mathrm{bp}$ ) of the Indonesian isolate with the Thai isolate. Additionally, there was a $100 \%$ identity in the real-time HPVth PCR target site. DNA from the 9 individual shrimp were analyzed by the duplex realtime PCR and showed a moderate level of HPV infection approximately $10^{5}$ copies per $\mu \mathrm{g}$ DNA; MBV was not detected in these shrimp (Table 3). positive for HPV and MBV and the quantities of MBV and HPV were about the same, on average at an order of $10^{6}$ copies/per $\mu$ g DNA (Table 3). We also analyzed their relationship and found no significant correlation $(\mathrm{p}=$ 0.7112) between HPV and MBV viral loads.

\section{DISCUSSION}

We developed a duplex real-time PCR assay for detecting and quantifying HPV and MBV infections in penaeid shrimp. Since the sequence of MBV real-time primers/probe binding site is identical in Taiwanese and Indian isolates, the protocol should be able to detect MBV in infected Penaeus monodon from SE Asia, but the general applicability regarding the HPV real-time PCRs remains to be tested. This is because HPV is found in several regions, and there is high genetic variation among geographic isolates. As a first step, in developing our duplex assay, we used a HPVth real-time PCR protocol that was based on a viral isolate from a Thail isolate providing reliable detection and accurate quantification of HPV in samples infected with this, or a closely related, isolate. Two other realtime HPV PCR methods, one based on an Australian isolate and another based a Korean isolate have been published (LaFauce et al. 2007b, Yan et al. 2010). From those studies, we know that the sequence alignments of the amplicons with the target sequence of the Thai isolate contain 15 mismatched nucleotides in the primers/probe binding sites (Fig. 1A,B). In particular, nucleotide mismatches in Australian HPV real-time PCR could significantly affect the detection or quantification of 5 other isolates because of the 3 to 4 mismatches at the $3^{\prime}$ end of the reverse primer (Whiley \& Sloots 2005). Our HPVth real-time protocol should work well with isolates from Malaysia and Indonesia. With our Thailand P. monodon samples, although there 
were 3 mismatched nucleotides in primers/probe binding sites, these mismatches are adenine to guanine transitions which are not near the $3^{\prime}$ end of the primers. Therefore, these mismatches probably will not affect either detection or quantification.

Our protocol proved useful in comparing viral load between normally grown shrimp and shrimp reported to have stunted growth. HPV has previously been suggested to be associated with growth retardation in $\mathrm{Pe}$ naeus monodon (Flegel et al. 1999). This association was determined by statistical analysis of shrimp size versus infection severity, as graded by histology (Flegel et al. 1999). By duplex real-time PCR, we found no significant difference in either HPV or MBV viral load among individual $P$. monodon of normal compared to stunted growth. This suggests that neither HPV nor MBV were responsible for stunted growth in our samples, so the stunted growth must be attributed to other factors.

In addition, we did not find a significant correlation between HPV and MBV viral loads as obtained by Flegel et al. (1999). Our data suggest that these 2 viruses replicated independently in the shrimp that were analyzed. From histological data (Lightner \& Redman 1985, Lightner 1996), we know that HPV preferentially infects E (Embryonalzellen)-cells of the hepatopancreas; since HPV does not encode DNA polymerase, it depends on the highly active host cells for replication. MBV, on the other hand, is a baculovirus that carries its own DNA polymerase and, thus, can replicate in B (Blasenzellen)-, F (Fibrenzellen)and $\mathrm{R}$ (Restzellen)-cells. It is unlikely that the 2 viruses would interact with each other.

Infection with either MBV or HPV at early developmental stages of both farmed and wild shrimp can lead to serious economic losses. MBV- and/or HPV-infected shrimp do not exhibit obvious clinical signs; therefore, infection cannot be detected by visual inspection. This inability to detect infected individuals can result in the rapid spread of these viruses. The duplex real-time PCR developed in the present study has shown to be both specific and sensitive allowing for detection and quantification of either of these 2 viruses, including coinfected shrimp, thus offering a valuable tool for routine diagnosis and quantification of MBV and HPV from both wild and farmed shrimp stocks.

Acknowledgements. This work was supported by the NOAA, Saltonstall-Kennedy Grant No. NA09NMF4270102, the Gulf Coast Research Laboratory Consortium Marine Shrimp Farming Program, USDA Grant No. USMSFD 2009/19851-UAZ, and a special grant from the National Fisheries Institute.

\section{LITERATURE CITED}

Aquatic Animal Disease Cards OIE (2007) Hepatopancreatic parvovirus disease. Aquatic Animal Disease Cards, 2007. World Organisation of Animal Health (OIE), Paris, available at www.oie.int/aac/eng/Publicat/Cardsenglish/ HepatopancreaticParvovirusCard2007_Revised92707_.pdf Bonami JR, Mari J, Poulos BP, Lightner DV (1995) Characterization of hepatopancreatic parvo-like virus, a second unusual parvovirus pathogenic for penaeid shrimps. J Gen Virol 76:813-817

Chantanachookin C, Boonyaratpalin S, Kasornchandra J, Direkbusarakom S and others (1993) Histology and ultrastructure reveal a new granulosis-like virus in Penaeus monodon affected by yellow-head disease. Dis Aquat Org 17:145-157

Chayaburakul K, Nash G, Pratanpipat P, Sriurairatana S, Withyachumnarnkul B (2004) Multiple pathogens found in growth-retarded black tiger shrimp Penaeus monodon cultivated in Thailand. Dis Aquat Org 60:89-96

Chong YC, Loh H (1984) Hepatopancreas chlamydial and parvoviral infections of farmed marine prawns in Singapore. Singapore Vet J 9:51-56

de la Pena LD, Lavilla-Pitogo CR, Villar CBR, Paner MG, Capulos GC (2008) Prevalence of monodon baculovirus (MBV) in wild shrimp Penaeus monodon in the Philippines. Aquaculture 285:19-22

> Flegel TW, Thamavit V, Pasharawipas T, Alday-Sanz V (1999) Statistical correlation between severity of hepatopancreatic parvovirus infection and stunting of farmed black tiger shrimp (Penaeus monodon). Aquaculture 174: 197-206

Flegel TW, Nielsen L, Thamavit V, Kongtim S, Pasharawipas T (2004) Presence of multiple viruses in non-diseased, cultivated shrimp at harvest. Aquaculture 240:55-68

La Fauce KA, Elliman J, Owens L (2007a) Molecular characterization of hepatopancreatic parvovirus (pmergDNV) from Australian Penaeus merguiensis. Virology 362:397-403

> La Fauce KA, Layton R, Owens L (2007b) TaqMan real-time PCR for detection of hepatopancreatic parvovirus from Australia. J Virol Methods 140:10-16

Lightner DV (1996) A handbook of shrimp pathology and diagnostic procedures for diseases of cultured penaeid shrimp. World Aquaculture Society, Baton Rouge, LA, p 304

Lightner DV, Redman RM (1981) A baculovirus-caused disease of the penaeid shrimp Penaeus monodon. J Invertebr Pathol 38:299-302

Lightner DV, Redman RM (1985) A parvo-like virus disease of penaeid shrimp. J Invertebr Pathol 45:47-53

> Manivannan S, Otta SK, Karunasagar I, Karunasagar I (2002) Multiple viral infection in Penaeus monodon shrimp postlarvae in an Indian hatchery. Dis Aquat Org 48:233-236

> Manivannan S, Kennedy B, Karunasagar I, Karunasagar I (2004) Prevalence of monodon baculovirus in wild Metapenaeus species along the southwest coast of India. Aquaculture 232:63-67

> Manjanaik B, Umesha KR, Karunasagar I, Karunasagar I (2005) Detection of hepatopancreatic parvovirus (HPV) in wild shrimp from India by nested polymerase chain reaction (PCR). Dis Aquat Org 63:255-259

> Mari J, Bonanmi JR, Poulos B, Lightner D (1993) Preliminary characterization and partial cloning of the genome of a baculovirus from Penaeus monodon (PmSNPV = MBV). Dis Aquat Org 16:207-215

Sukhumsirichart W, Attasart P, Boonsaeng V, Panyim S (2006) Complete nucleotide sequence and genomic organization of hepantopancreatic parvovirus (HPV) of Penaeus monodon. Virology 346:266-277

> Surachetpong W, Poulos BT, Tang KFJ, Lightner DV (2005) Improvement of PCR method for the detection of monodon baculovirus (MBV) in penaeid shrimp. Aquaculture 249: $69-75$ 
Tang KFJ, Pantoja CR, Lightner DV (2008) Nucleotide sequence of a Madagascar hepatopancreatic parvovirus (HPV) and comparison of genetic variation among geographic isolates. Dis Aquat Org 80:105-112

- Umesha RK, Uma A, Otta SK, Karunasagar I, Karunasagar I (2003) Detection by PCR of hepatopancreatic parvovirus (HPV) and other viruses in hatchery-reared Penaeus monodon postlarvae. Dis Aquat Org 57:141-146

Whiley DM, Sloots TP (2005) Sequence variation in primer

Editorial responsibility: Grant Stentiford,

Weymouth, UK targets affects the accuracy of viral quantitative PCR. J Clin Virol 34:104-107

Yan D, Tang KFJ, Lightner DV (2009) Development of a real-time PCR assay for detection of monodon baculovirus (MBV) in penaeid shrimp. J Invertebr Pathol 102: $97-100$

Yan DC, Tang KFJ, Lightner DV (2010) A real-time PCR for the detection of hepatopancreatic parvovirus (HPV) of penaeid shrimp. J Fish Dis 33:507-511

Submitted: July 1, 2010; Accepted: September 29, 2010

Proofs received from author(s): December 8, 2010 